\title{
A simulation of integrated photovoltaic conversion into electric grid
}

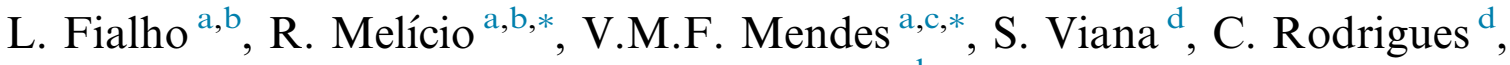 \\ A. Estanqueiro ${ }^{\mathrm{d}}$ \\ ${ }^{a}$ Department of Physics, Universidade de Évora, R. Romão Ramalho 59, 7002-554 Évora, Portugal \\ ${ }^{\mathrm{b}}$ IDMEC/LAETA, Instituto Superior Técnico, Universidade de Lisboa, Avenida Rovisco Pais, 1049-001 Lisbon, Portugal \\ ${ }^{\mathrm{c}}$ Department of Electrical Engineering and Automation, Instituto Superior de Engenharia de Lisboa, R. Conselheiro Emídio Navarro, 1950-062 \\ Lisbon, Portugal \\ ${ }^{\mathrm{d}}$ National Laboratory of Energy and Geology, Estrada do Paço do Lumiar, 1649-038 Lisbon, Portugal
}

Received 8 July 2014; received in revised form 22 September 2014; accepted 27 September 2014

Communicated by: Associate Editor Nicola Romeo

\begin{abstract}
This paper presents a systemic modeling for a PV system integrated into an electric grid. The modeling includes models for a DC-DC boost converter and a DC-AC two-level inverter. Classical or fuzzy PI controllers with pulse width modulation by space vector modulation associated with sliding mode control is used for controlling the PV system and power factor control is introduced at the output of the system. Comprehensive performance simulation studies are carried out with the modeling of the DC-DC boost converter followed by a two-level power inverter in order to compare the performance with the experimental results obtained during in situ operation with three commercial inverters. Also, studies are carried out to assess the quality of the energy injected into the electric grid in terms of harmonic distortion. Finally, conclusions regarding the integration of the PV system into the electric grid are presented.
\end{abstract}

(C) 2014 Elsevier Ltd. All rights reserved.

\section{Introduction}

Electricity market restructuring brought a different running set to the energy power system business, not only at the level of energy conversion, but also at the level of energy use (Cucchiella and D'Adamo, 2013). Since restructuring and the environmental concern on anthropogenic emission has arrived at this business, developments in distributed power generation systems (PGSs) allowed for the

\footnotetext{
* Corresponding authors at: Department of Physics, Universidade de Évora, R. Romão Ramalho 59, 7002-554 Évora, Portugal. Tel.: +351 266 745372; fax: +351 266745394 .

E-mail addresses: ruimelicio@uevora.pt (R. Melício),vfmendes@deea. isel.pt (V.M.F. Mendes).
}

integration of renewable energy conversion, allowing a never seen before incentive to profit from renewable energy and an increment of mixed conversion into energy power systems (Peças Lopes et al., 2007; Liu et al., 2014). Nowadays, distributed PGSs are a reality on, for instances: solar energy exploitation by photovoltaic, concentrator solar and integrated solar combined cycle systems; wind energy exploitation by onshore and offshore wind turbines. A report on hardware and on control, including grid synchronization for distributed PGSs are given in Blaabjerg et al. (2004) and in Blaabjerg et al. (2006), respectively.

The increasing integration of distributed PGSs will change considerably the dynamic behavior of the energy power system in comparison with the forerunner one (Erlich et al., 2007). Actions have to be envisaged against 